\title{
Tracheal Laceration Due to Elective Intubation and Its Treatment with Endotracheal Stenting
}

\author{
Aybüke Kekeçoğlu ${ }^{1}$, Cengiz Özdemir' ${ }^{1}$ Levent Karasulu ${ }^{1}$, Ayşe Filiz Koşar¹, \\ Levent Dalar ${ }^{2}$ \\ ${ }^{1}$ Clinic of Chest Diseases, Yedikule Chest Diseases and Thoracic Surgery Training and Research Hospital, İstanbul \\ ${ }^{2}$ Department of Chest Diseases, İstanbul Bilim University Faculty of Medicine, İstanbul
}

\begin{abstract}
Tracheal laceration as a result of elective intubation is a rarely seen complication with a high mortality. An eighty-one years old, female patient who was followed in the intensive care unit and treated with mechanical ventilation, developed subcutaneous emphysema after intubation. Fiberoptic bronchoscopy performed via the endotracheal tube revealed laceration in the trachea $5 \mathrm{~cm}$ in length.. The urgent rigid bronchoscopy has been performed and one silicone straight stent and a covered metallic bifurcated stent have been inserted. The araea of laceration has been covered totally. The subcutaneous emphysema disappeared incrementally and after weaning period the patient discharged to the ward.
\end{abstract}

Keywords: Bronchoscopy, complication, intensive care, tracheal lace - ration

Received Date: 23.09 .2013 Accepted Date: 07.12.2013 Available Online Date: 01.04.2015

Address for correspondence Levent Dalar

E-mail: leventdalar@yahoo.com (1) 8 This work is licensed under a Creative 4.0 International License.

DOI: 10.5152/ejp.2014.48992

- Available online at www.eurasianjpulmonol.com

\section{INTRODUCTION}

Tracheal laceration can be caused by trauma or iatrogenic reasons. Subcutaneous emphysema is observed in almost all cases and the final diagnosis is established by identifying a laceration or rupture via bronchoscopic examination. The main treatment option in tracheal laceration is surgical, but conservative approaches can be applied in selected cases. Considering the age, additional diseases, and the urgency of the present situation, our case was deemed unsuitable for surgery and tracheal stent was applied. Verbal and written consents were taken from the patient and relatives.

\section{CASE PRESENTATION}

An 81-year-old female patient was admitted to our emergency polyclinic with respiratory distress. Upon discovering respiratory acidosis in her arterial blood gas, she was intubated and admitted to the respiratory intensive care unit after losing consciousness following an unsuccessful noninvasive mechanical ventilation support. Her history included valvular heart disease, atrial fibrillation, hypertension, and chronic obstructive pulmonary disease. In her physical examination during admittance to the intensive care unit, her general condition was bad, she was unconscious, both hemithoraces participated in respiration equally, expiration in bilateral lungs was long, and breath sounds were diminished. Bilateral pretibial edema was present. Subcutaneous emphysema, more prominent in the right hemithorax, was present, extending to the neck. Arterial tension was $145 / 100 \mathrm{mmHg}$, cardiac apex beat was 137 per minute, and temperature was 36.8 degrees. In the arterial blood gas, the $\mathrm{pH}$ was $7.19, \mathrm{pCO}_{2}$ was $81 \mathrm{mmHg}, \mathrm{pO}_{2}$ was $65 \mathrm{mmHg}$, oxygen saturation was $91 \%$, and $\mathrm{HCO}_{3}$ was 32 $\mathrm{mmoL}$. The patient was taken into mechanical ventilation support with the following values in pressure control mode: PEEP: 6 mbar, over PEEP pressure: 26 mbar, respiratory rate: 15 , and $\mathrm{FiO}_{2}: 60 \%$. In the laboratory tests, platelet was $24,000 / \mathrm{mm}^{3}$, preprandial blood glucose was $192 \mathrm{mg} / \mathrm{dL}$, urea was $124 \mathrm{mg} / \mathrm{L}$, creatinine was $1.7 \mathrm{mg} / \mathrm{dL}$, and other parameters were within normal ranges. These findings led to the suspicion of pneumonia and sepsis in the patient. Considering that elective intubation in the emergency room could lead to tracheal injury, first a chest radiography was performed. On the chest radiography that was taken lying down, severe increase in the cardiothoracic ratio in favor of the heart, increase in opacity in the bottom right area compatible with possible pneumonic 


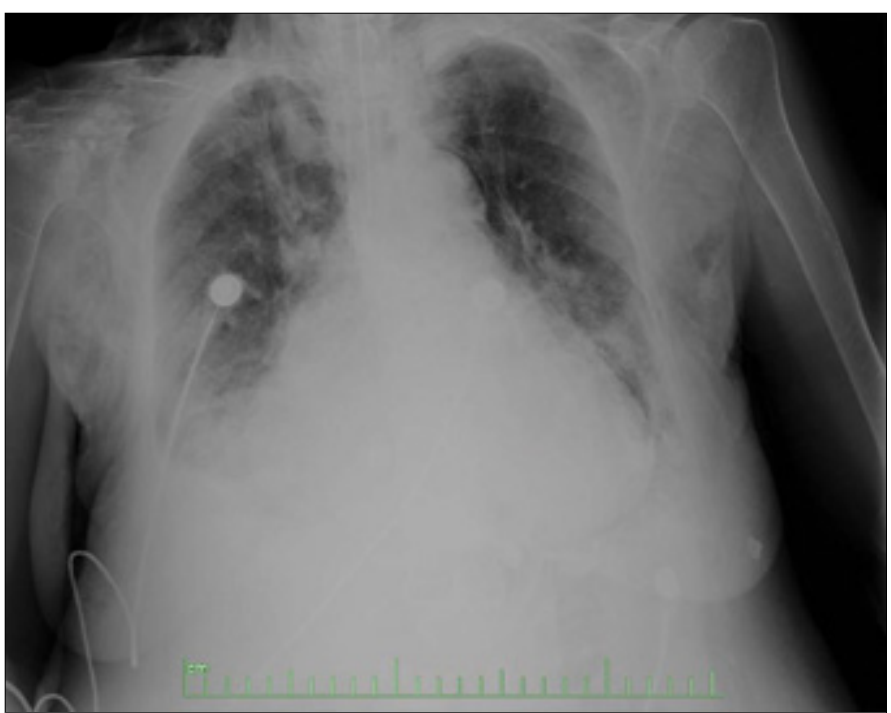

Figure 1. Chest x-ray at the admission of the patient to the intensive care unit

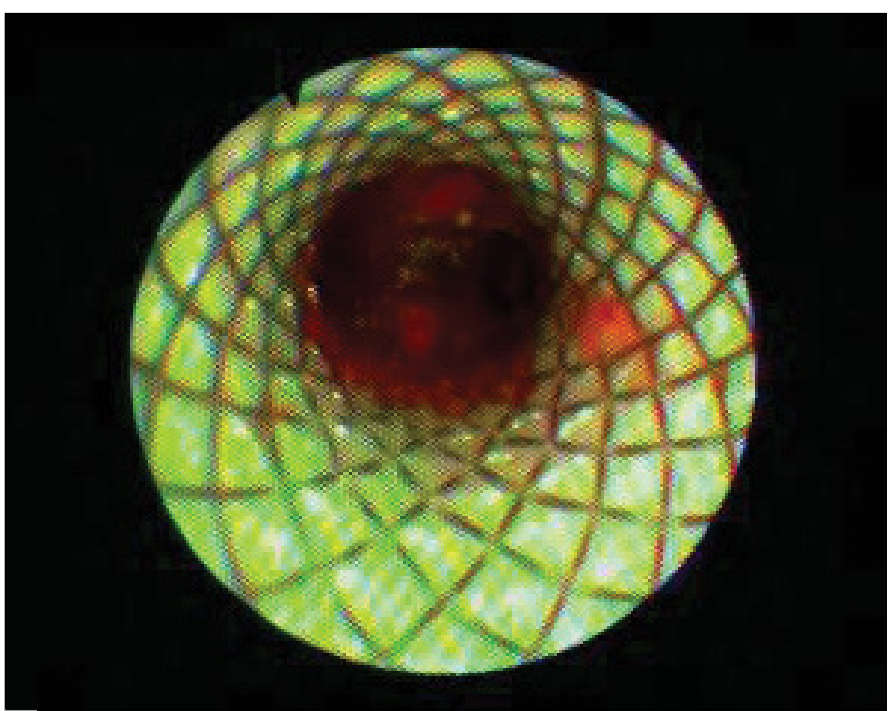

Figure 3. Appearance of the trachea after stent application

consolidation, and bilateral, but more prominent in the right that is observed to extend up to the neck, subcutaneous emphysema and pneumomediastinum were observed (Figure 1). After partially stabilizing the patient's general condition, fiber optic bronchoscopy was performed in order to determine the cause of the subcutaneous emphysema. Prior to bronchoscopy, the platelet level was elevated to $102.000 \mathrm{~mm}^{3}$ via 8 units of platelet replacement. Bronchoscopy revealed normal localization of endotracheal tube, normal carina, open bilateral main bronchus, and hemorrhagic left bronchus system. When the endotracheal tube was retracted and the trachea was examined, a tear area of approximately $4-5 \mathrm{~cm}$ was discovered in the tracheal right posterolateral wall. The patient was scheduled for emergency rigid bronchoscopy. In the rigid bronchoscopic examination, laceration area and mediastinal fistula were observed along the line on the tracheal wall starting from a distance of $5 \mathrm{~cm}$ from the vocal chords and continuing along the right posterolateral edge for about $5 \mathrm{~cm}$ (Figure 2). From this area, it was

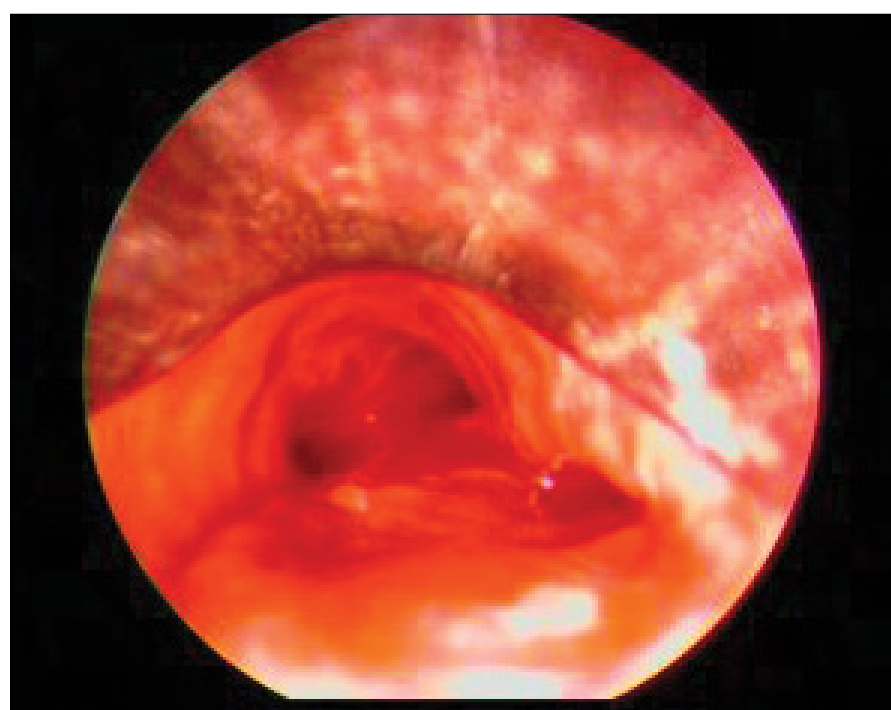

Figure 2. Rigid bronchoscopy revealed a rupture area in the right posterolateral wall

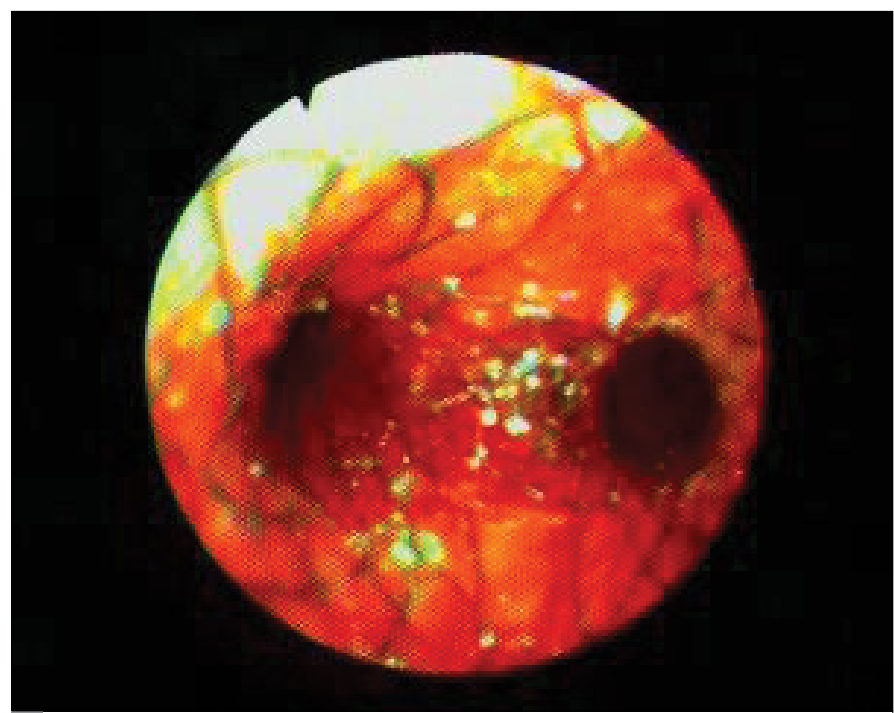

Figure 4. Bronchoscopic appearance of tracheal distal, carina, and main bronchus entries after stent placement

observed that a hemorrhage in the form of a leakage had occurred and that this laceration area ended $2 \mathrm{~cm}$ away from the carina. In order to cover tracheal laceration and the fistula area, an $18 \times 50 \mathrm{~mm}$ silicon stent was placed in the lumen. The mucosa of the laceration area was fragile and atrophic, and because it was thought that the laceration will progress from the bottom end of the stent to the distal trachea, $16 \times 12 \times 12 \mathrm{~mm}$ metallic $Y$ stent was placed to the right and left primary bronchia by opening the silicon inside the stent (Figures 3,4). Stent patency was established. The process was finalized by placing the endotracheal tube immediately in alignment with the edge of the silicon stent following the bronchial washing. The patient was successfully extubated on the $8^{\text {th }}$ day of intubation. The weaning process was completed by intermittent noninvasive mechanical ventilation support. The patient's general condition improved and mediastinal and subcutaneous emphysema completely disappeared. She was discharged into the service from the respiratory intensive care unit (Figure 5). 


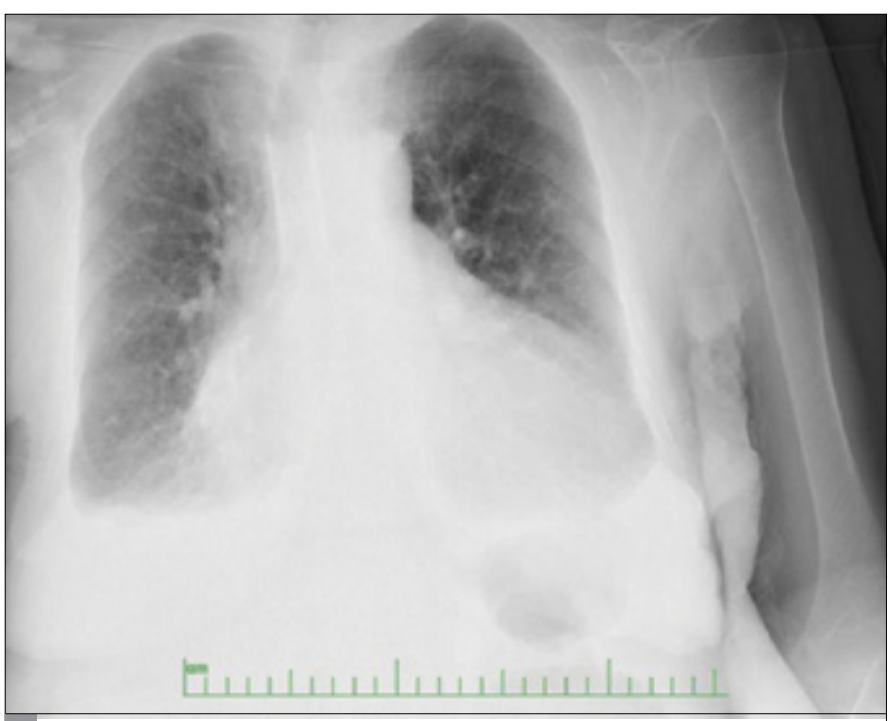

Figure 5. X-ray radiography at discharge from respiratory intensive care unit. Complete disappearance of subcutaneous emphysema is seen

\section{DISCUSSION}

Tracheal laceration can be caused by blunt trauma, penetrating injuries, firearm injuries, and iatrogenic reasons.

The most commonly observed iatrogenic reason is intubation. It can develop during single or double lumen intubation. Its incidence after orotracheal intubation is $0.005 \%$ and this ratio changes to between $0.05 \%$ and $1.9 \%$ for double lumen intubation $(1,2)$. It has the following among its etiology: lack of experience of the personnel that intubate and recurring intubation attempts, over inflammation of the endotracheal tube cuff, changing the tube's place when the cuff balloon is inflated, malposition of the guide wire, failure to choose an appropriately sized endotracheal tube, and trachea anomalies (3). Although penetrating injuries are commonly observed in the cervical region, laceration and rupture more often occur in the distal trachea and primary bronchia following intubation. Rupture is generally in the joint of the membranous and cartilage parts and is linear. In women and especially, in short cases, the risk is shown to be significantly higher (1, $2,4,5)$. The most commonly observed physical examination findings in tracheal rupture cases are respiratory insufficiency, subcutaneous emphysema, and hemoptysis. The first diagnostic step is radiography of the pulmonary and cervical region. The pneumothorax and pneumomediastinum has been observed can be observed in chest X-ray and in tomography. Subcutaneous emphysema is observed in almost all tracheal laceration cases. However, in $10 \%$ of the acute period cases, no radiological findings are observed. Computed tomograhy can reveal the laceration in the patients with appropriate clinics. Final diagnosis of tracheal rupture is established by bronchoscopy. Rigid or flexible bronchoscopy may be used. Bronchoscopy must be performed as soon as possible and it must include the area under the intubation tube of the intubated patient. In previous studies, it is noted that $50 \%$ of the lesions can be overlooked in the first bronchoscopic examination. Therefore, if suspicion persists, the process can be repeated, even if the first bronchoscopic findings are normal $(2,3-6)$.

Surgical approach is the initial treatment choice in most of the cases and is recommended in order to prevent the development of mediastinitis in the early period and of tracheal stenosis in the late period.
Although, in general, right thoracotomy is used, a transcervical approach is recommended in proximal ruptures (6-8).

Although the main treatment choice is surgery, it is reported in the literature that tracheal lacerations due to intubation can be treated by conservative methods. Conservative treatment can be applied to patients that the laceration is shorter than $2 \mathrm{~cm}$ and patients who are uncomplicated and stable. In the conservative treatment, the tip of the intubation tube is placed under the rupture, and it is followed up with appropriate antibiotic treatment. Because the conservative treatment approaches have improved and their usability had increased in recent years, tracheal stent applications are reported among the conservative treatment approaches $(10,11)$. In our case, considering the patient's age, additional diseases, her general condition not being appropriate for surgery, and the urgency of the present clinic, conservative treatment is considered as a priority $(3,5,9-11)$. Main steps of the treatment process are the complete covering of the laceration area, prevention of the growth with a stent, and keeping the endotracheal tube in distal. The case is currently followed up in the $5^{\text {th }}$ month of her treatment. Although the optimal duration for the stent to remain in place is unknown, 6-12 months can be argued as sufficient given the experience of the center.

\section{CONCLUSION}

In conclusion, endotracheal stenting in iatrogenic trachea lacerations should be considered as an effective treatment option.

Informed Consent: Informed consent was obtained from patient who participated in this case.

Peer-review: Externally peer-reviewed.

Author contributions: Concept - A.K., C.Ö.; Design - A.K., L.D.; Supervision L.D., F.K.; Resource - L.D., A.K.; Materials - C.Ö., L.K.; Data Collection \&/or Processing - A.K., C.Ö.; Analysis \&/or Interpretation - L.D.; Literature Search - A.K.; Writing - A.K., C.Ö., L.D.; Critical Reviews - L.D., F.K.

Conflict of Interest: No conflict of interest was declared by the authors.

Financial Disclosure: The authors declared that this study has received no financial support.

\section{REFERENCES}

1. Borasio $\mathrm{P}$, Ardissone $\mathrm{F}, \mathrm{Chiampo}$ G. Post-intubation tracheal rupture. A report on ten cases. Eur J Cardiothorac Surg 1997; 12: 98-100. [CrossRef]

2. Massard G, Rougé C, Dabbagh A, Kessler R, Hentz JG, Roeslin N, et al. Tracheobronchial lacerations after intubation end tracheostomy. Ann Thorac Surg 1996; 61: 1483-7. [CrossRef]

3. Ozgulder A. Trakeobronşiyal Yaralanmalar. TTD Toraks Cerrahisi Bülteni 2010; $1: 1$.

4. Conti M, Pougeoise M, Wurtz A, Porte H, Fourrier F, Ramon P, et al. Management of postintubation tracheobronchial ruptures. Chest 2006; 130:412-8. [CrossRef]

5. Karadayı Ş, Yazııı Ü, Gülhan E, Taştepe I, Altınok T, Ege T. Trakeobronşiyal Yaralanmalarda Tedavi Yaklaşımlarımız. Solunum Hastalıkları 2007; 18: 114-7.

6. Hahn B. Tracheobronchial rupture. J Emerg Med 2007; 33: 193-4. [CrossRef]

7. Grillo HC. Tracheal and bronchial trauma. In Grillo HC ed.Surgery of the trachea and bronchi. London B.C. Hamilton Inc, 2004: 271-90.

8. Kiser AC, O'Brien SM, Detterbeck FC. Blunt tracheobronchial injuries: treatment and outcomes. Ann Thorac Surg 2001; 71: 2059-65. [CrossRef]

9. Karmy-Jones R, Avansino J, Stern EJ. CT of blunt tracheal rupture. AJR Am J Roentgenol 2003; 180: 1670. [CrossRef]

10. Osorio García F, Serrano Alvarez C, Martinez Sánchez A, Gallardo Medina M. Post-tracheal intubation rupture treated with a Dumon-Y stent. Rev Esp Anestesiol Reanim 2012; 59: 171-2.

11. Yopp AC, Eckstein JG, Savel RH, Abrol S. Tracheal stenting of iatrogenic tracheal injury: a novel management approach. Ann Thorac Surg 2007; 83: 1897-9. [CrossRef] 